\title{
Plans for marine protection highlight science gap
}

Researchers are scrambling to understand how best to deploy conservation zones.

\section{BY DANIEL CRESSEY}

$\mathrm{F}$ acing a host of threats including fishery devastation and the destruction of coral reefs, conservationists have increasingly pinned their hopes on marine protected areas (MPAs). More than 5,000 of these sanctuaries, where fishing is controlled to limit its effect on biodiversity, have been set up, mainly in coastal zones. They range in size from less than 10,000 square metres to the vast Phoenix Islands area, part of the Republic of Kiribati in the Pacific Ocean, which tops 400,000 square kilometres.

But, in the rush to safeguard marine ecosystems, there has been little scientific assessment of how to create a successful MPA. With a new wave of MPAs expected to be created in deep-ocean regions in the next few years, scientists are eager to understand how factors such as size and siting can determine a protected area's success or failure.

Tundi Agardy, an environmental consultant based in Colrain, Massachusetts, is the lead author of a paper ${ }^{1}$ published in Marine Policy, which warns of a "blind faith" in the ability of MPAs to stem biodiversity loss. She told Nature that she can name only "a handful" of areas that actually work as advertised. Her paper identifies five possible shortcomings in MPAs: many are too small to be effective; they may simply drive fishing into other areas; they create an illusion of protection when none is actually occurring; many are poorly planned or managed; and they can fail all too easily because of environmental degradation of waters just outside the protected area.

"I'd venture a guess that a majority of the world's several thousand MPAs have one flaw or another relating to the five categories we describe," says Agardy. For example, an MPA created to protect the vaquita (Phocoena sinus), a small porpoise found only in the Gulf of California, actually missed a sizeable proportion of the species' core range. The animal's numbers have continued to decline and it is now the most endangered marine mammal in the world ${ }^{2}$.

"We still need a lot of knowledge to really understand how MPAs work exactly," says Frederic Vandeperre, a marine biologist at the University of the Azores in Horta who last month published an analysis ${ }^{3}$ of seven southern European MPAs. The study showed that these MPAs can benefit fisheries in adjacent waters,

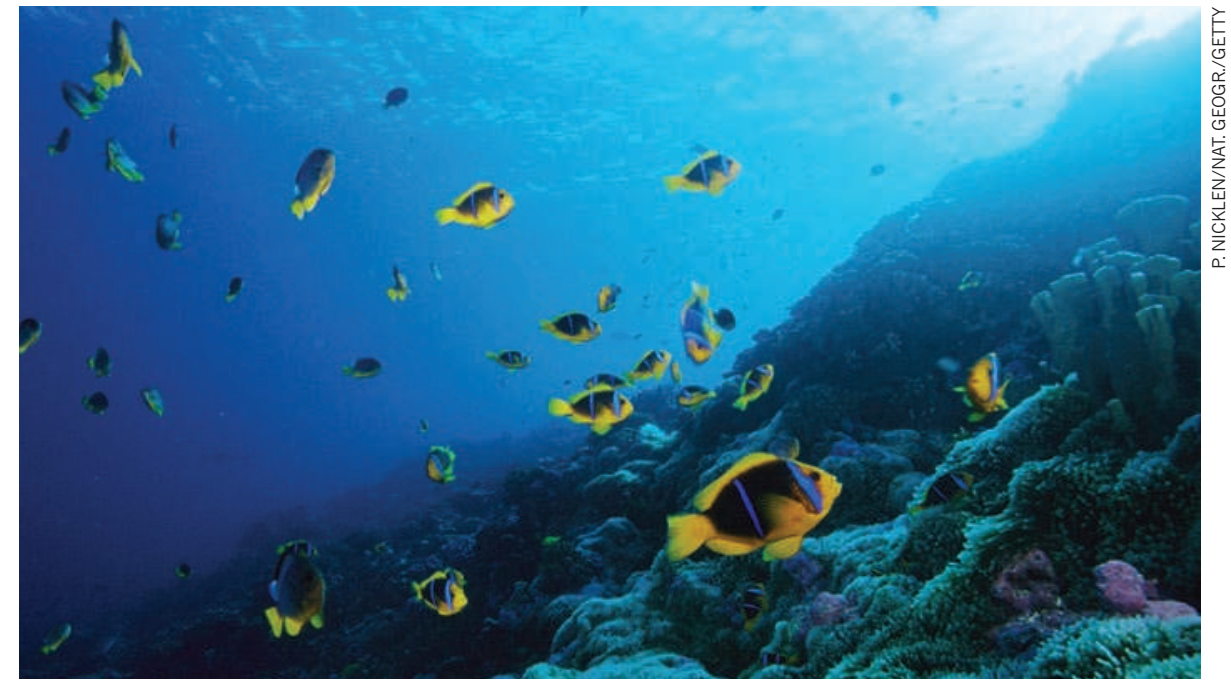

The reefs of the Phoenix Islands in Kiribati are part of the world's largest marine protected area.

but that the degree of the effect depends heavily on the size of the area and the quality of its management. Vandeperre says that each MPA needs a unique design, depending on its goals. For example, those that explicitly aim to safeguard fishing yields need to cover a larger area.

\section{INTERNATIONAL WATERS}

Conservationists should approach the design and siting of an MPA as an experiment, he says. "We should maybe create MPAs with different structures, different designs in a controlled way, to be really like an experiment so we can figure out which elements are crucial." This could include variations in size, location, management strategy, monitoring and proximity to other MPAs.

Understanding the best way to create MPAs is about to become much more important. The 2002 World Summit on Sustainable Development set ambitious, internationally agreed targets to establish extensive networks of MPAs around the world by 2012 .

This requires the creation of more MPAs outside national boundaries in the high seas, where still less is known about how to make them work. "We have almost no experience of applying marine protected areas to high-seas ecosystems," says Alex Rogers, a conservation ecologist at the University of Oxford, UK. "We don't really know where to put them. We suspect that simply by placing them in places that are particularly sensitive for species we may be able to derive a considerable management benefit, but it's very, very early days at the moment." Rogers is organizing a conference at the Zoological Society of London next month to discuss the design of high-seas protected areas, along with the complex legal and political issues that surround them.

Still, some studies are starting to give clear pointers on the best way to position both coastal and high-seas MPAs. Last month, Mark Christie of Oregon State University in Corvallis and his team published an analysis ${ }^{4}$ showing that fish larvae - those of the yellow tang (Zebrasoma flavescens) - were successfully dispersing from an MPA to sites up to 180 kilometres away.

"Now we are able to show the larvae can drift to sites outside the MPA and essentially reseed fish stocks significant distances away," says Christie. The result means that by combining information about ocean currents with the genetics of larvae captured from the seas, researchers can identify from where the larvae came. That could help pinpoint - and protect - the most important spawning areas for species such as Pacific bluefin tuna (Thunnus orientalis), says Rogers..

1. Agardy, T., Notarbartolo di Sciara, G. \& Christie, P. Mar. Policy 35, 226-232 (2011).

2. Dalton, R. Nature $465,674-675$ (2010).

3. Vandeperre, F. et al. Fish Fish. doi:10.1111/j.1467-

2979.2010.00401.x (2010).

4. Christie, R. et al. PLoS One 5, e15715 (2010). 